\title{
An Approach to the Model of Turning Classroom Teaching under the Guidance of Self - study in Japanese Teaching of Independent College
}

\author{
Man Zhang \\ Wuhan University of Communications, 430205, Wuhan, China \\ zhangmanwh@163.com
}

Keywords: Turning classroom; Self - study; Japanese Teaching; Independent College; Guidance

\begin{abstract}
Turning classroom is an upside - down classroom mode, paying attention to giving students a full study of free space, extending knowledge transfer to classroom, promoting students to use diverse learning methods to effectively absorb new knowledge while focusing on knowledge within the classroom. Turning the classroom "makes the teacher become the facilitator and the instructor of learning from the knowledge transfer of the traditional classroom, and becomes a scaffold for students to easily acquire resources, use resources, process information and apply knowledge. The paper presents An Approach to the Model of Turning classroom teaching under the Guidance of Self - study in Japanese Teaching of Independent College.
\end{abstract}

\section{Introduction}

Flip the classroom is in the environment of information, teachers to provide teaching video as the main form of learning resources, students of teaching video learning resources to watch and learn before class, teachers and students to complete homework and answering in class together, a new teaching mode and collaborative inquiry interaction activities. The basic idea of this the teaching mode of "student centered", its core is "let every student learn at their own pace, two is the personalized guidance interaction. Teacher training has pertinence, content generalization, single mode, weak quality control and other issues [1]. There are many reasons for not strong problem, which may include: not to the teachers as the center, but in the training center; the lack of multi subject interaction; individual guidance and follow-up" turn class absence. The concept of "Hall" is a useful reference for solving the problem of current teacher training.

The policy and task drive under the background of "Internet" may urge the educational administration to pay more attention to the network education resources and means to infiltrate into the school education. Combined with classroom application and teaching practice, this paper compares and analyzes the characteristics and functions of network teaching and classroom teaching. The analysis shows that classroom and network are very different fields for teachers. The interaction of students and teaching will have different effects. Classroom teaching should deal with the new changes of educational ecology rationally and actively, stick to the open attitude and value, and choose carefully on the basis of comparison and balance.

Today, the Internet has penetrated into the daily life in the micro field, in the macro field, but also triggered industrial innovation, leading to a strong engine of new forms of business, with the help of Internet platforms and information and communication technology. In recent years, new educational resources, new forms and new models have emerged. Related academic research and teaching practice continue to heat up. With the "Internet" action was written in 2015, the Government work report. "Internet education" will become a new focus and research topic. How to rationally analyze and actively respond is to the new changes of educational ecology under the background of "Internet" in school education. How to make use of the innovative achievements of the Internet to help improve the quality of school education is an important issue worthy of deep consideration and careful planning.

State leaders have stressed on many occasions that the whole party and the whole country should 
take positive actions, persist in educating people, take reform and innovation as the motive force, focus on promoting fairness, and focus on improving quality [2]. To promote the scientific development of education at a new historical starting point, and to accelerate the pace from a big educational country to a powerful educational country, we must conscientiously implement the Party's educational policy, thoroughly implement the scientific concept of development, and persist in educational reform.

To promote the development of the country and the nation, to adopt the proper educational means, the proper educational method and the content, to change the educational idea, and then to realize the true educational significance of the education, thus the practice of the educational form. The reform of educational methods, the renewal of educational concepts, the enrichment and adjustment of educational contents, and so on, have already penetrated into every school, every family and so on. Because education is development, education is the destiny of the country, and education is the future. Taking information technology as the basic condition of optimizing education, insisting on the innovation of educational idea and the innovation of educational method, therefore, the exploration of new educational idea and new educational method makes us solve the urgent problems in the field of education at present.

With the deepening of the teaching reform, the emergence of new teaching mode and method of multi characteristic will flip the classroom teaching mode applied to senior high school physics teaching, is an effective way to make the classroom innovation. Flip classroom teaching mode to effectively play its utility, cannot do without the scientific teaching module design, and puts forward the some new requirements for teachers and students; we need to conduct detailed inquiry.

\section{Turn - over Classroom Teaching Mode Guided by Self - study}

Teacher training needs to the teachers as the center. Effective teacher training should be based on the teachers' autonomous learning based training to teachers' participation in training. Whether teachers' vocational training or job training, learners do not have active participation, lack of autonomy, the real learning activities did not happen. What about the learning effect? Participating in the training teacher centered training, first of all to achieve participation, should according to the characteristics of learning, teachers learning needs, focus on practical problems, the teachers design teaching, activities of the organization.

"Flip the classroom for change of teacher education, especially vocational expert (part-time training) training center for the status quo will undoubtedly have a great impact [3]. One is the need to provide learning resources to the teachers before the training, to put an end to" setup Courses "," class for tracing, looking for to undertake the training task of teaching training. The two is to put forward the challenge to the training of ability and quality, can not provide training before class learning resources will not be able to do.

The three is used to teach the method of training, must change the teaching idea and method, pay attention to training of teachers learning needs and the actual positions. Otherwise, even if provided before class learning resources, it is difficult to cope with the training classroom questioning and targeted guidance. The four is to promote the training of teachers must download learning resources before training by means of network, submit pre operation (ask The case, etc.), ready to do professional training; otherwise, the training will not participate in professional dialogue. This will enable the teachers automatically to stimulate learning motivation and initiative online learning skills, and consciously combing before training learning resources, learning to prepare for training.

Moo is the most important carrier of network education. It breaks the limitation of classrooms, surmounts the walls of colleges and universities, and makes knowledge open to all. 2012. The U. S. Udacity \#en0\# Courseraed X was set up one after another and soon became the most influential supplier of Movemo platform.

In May 21st 2013, Peking University of China. Tsinghua joined edX on the same day, and published its own courses on the platform. Domestic institutions of higher learning quickly followed, Shanghai Jiaotong University, Fudan University, Tongji University and other "985" schools. The 
National University of Taiwan and the University of Hong Kong all joined one of the three major platforms in the same year. Domestic platforms for such courses were also launched in succession, such as NetEase Clouds, and Weibo School online [4].

In 2014, "Love course" and NetEase's "Chinese University MOOC" platform were officially launched. At present, there are 340 online courses in 39 universities. Micro-video is the main form of microcourses in the United States. Through Khan College and TED-Ed network promotion has quickly become the basic learning unit in the environment.

In recent years, many micro-lesson websites at home and abroad have introduced various types of micro-lessons. In 2013 alone, four national microcourses (teaching) competitions were held, covering all stages of education in primary and secondary schools.

The practice of flipping classroom teaching reform is a beneficial attempt to combine information construction with classroom teaching. It is understood that the flipping classroom teaching experiment is in universities and middle schools all over the country. Primary schools have different levels of development, the scale of the experiment has classes, grades and even the whole school to participate, experimental subjects have liberal arts, science, information technology, Shandong Changle No. 1 Middle School in September 2014 to achieve in the whole school.

The whole subject-wide flipping classroom is now the first in china. Each school has summed up a lot of local teaching models, such as "two two, four steps, ten links" model. [2], "online tutoring" model. [3], "hybrid teaching based on flipping classroom", etc. [At the same time, it has caused a series of controversies about teacher's role, curriculum model, management mode and so on.

Perhaps it can be said that classes, microclasses, and flipping classes are the "new pet of education" created by the Internet, and the campus "three lessons"-classrooms, courses, and textbooks will realize "network transformation," and textbooks will be transformed into network resources. The curriculum is transformed into an admiration class, the campus classroom is transformed into a flipped classroom, and further further.

Second, can let the students mathematics foundation is weak if the class cannot understand, class can "kaixiaozao" the teacher, can repeatedly watch the video, and then to understand the consolidation of knowledge. Third, before class micro courses can let the students fully understand the teaching content, so that we can guarantee the class teachers and students interaction time, more attention to all students, and then carry out classroom answering doubts, fully embodies the teaching and learning through teaching.

\section{Discussion on Japanese Teaching in Independent College}

Effective teacher training should be guided by the self-orientation of participating teachers and multi-directional and interactive training of participating teachers. The performance of effective training lies in achieving problem-solving and behavioral improvement. In the process of self-monitoring, self-reflection and self-discovery, the self-directed "self" is not only individual but also collective; When the individual needs of the teachers meet the needs of the group, the training guidance will be universal and more effective.

In the traditional sense, the teacher training classroom pays attention to the unified information and ignores the individual differences; The mode of information transmission is monomial, ignoring the interaction of multiple subjects [5]. "flipping classroom" is due to the full time in class, which provides the possibility for the interaction between the subjects of teaching and learning, learning and learning. Because the pre-assignment provides the content and the object for the individualized instruction. If the trainer will have the general question as the topic of the training classroom, or will have the typical case as the topic of the training activity. It can promote the discussion and exchange of experiences among the teachers, and the trainers themselves often benefit from it.

This kind of training class forces the trainers to not be able to use "a lecture paper" to set their own problems. Self-questioning and self-answering "; The trainer must carefully study the pre-homework of the teachers before class, analyze the questions posed, distinguish the main questions from the individual questions, and carry out the whole class's key solutions and individual pertinence guidance 
respectively. Careful selection of typical cases, leading group discussions and class exchanges. The problem of inadequate guidance in the classroom, the study of insufficient cases, will be extended to extracurricular, after training, to facilitate the trainer's follow-up guidance or even follow up after the training. The realization of face-to-face or network interaction between teachers.

They are free time enough, in addition to teaching mathematics knowledge is not high, does not require students to learn by analogy, but to master the basic concepts, the concept of the corresponding examples. Even so, students still cannot guarantee the class time, students sometimes to go out for a long time will delay the entry class, traditional teaching is very difficult they help, students become students with learning difficulties; some of the students is the foundation of the foundation is weak, the teacher of "desertion" or "Duke of dating", low efficiency and no Work. And flipping the classroom needs the teachers before class upload micro class way, to ensure that students can watch this video whenever and wherever possible, can make students during the competition can also know teachers.

In the future Intel future classroom design in the United States has designed the future of our contemporary students what the classroom is the most important link is the production of micro-classes and the interaction of students in the classroom. So that students become the main body of the classroom, teachers also change their previous identities, go down the classroom to become students' partners, become students' guides and collaborators.

Leading the pack is Khan College, founded by Salman Khan, a young American who has tried to use Internet videos for teaching and learning in different places. Video device recorded about 10 minutes of teaching video uploaded to the Internet for people around the world for free use, the initial realization of the classroom flipping [6]. At the same time. In 2008, the concept of "2012 free first-class education for the whole world-flipping classroom" was formally put forward. After that, foreign countries not only made a lot of attempts and explorations on the educational practice. There is also a lot of research on micro-curriculum and "flipping classroom" in education and teaching theory. The need of interpersonal interaction in flipping classroom is the student-centered learning theory that determines the interactive form of classroom activities. Combined with the display teaching method decided by teacher-centered learning theory, which can realize automation with computer technology, the "flip classroom" is produced together.

\section{An Approach to the Model of Turn - over Classroom Teaching under the Guidance of Self - study in Japanese Teaching of Independent College}

Flipping classroom is different from the traditional classroom mode, it is a kind of inverted classroom model. It pays attention to giving students enough free space to learn, and extends the knowledge teaching to the outside of the classroom. Encourage students to use a variety of learning methods to effectively absorb new knowledge, while focusing on the internalization of knowledge in the classroom, in the process, further deepen the teacher-student relationship. It is a kind of teaching mode based on the status of students' main body of study that the teacher's knowledge is transferred from the teacher's knowledge to the students' knowledge learning in the flipping classroom. It is helpful to improve the pertinence and effectiveness of students' knowledge learning.

First, the information teaching environment provides a platform for the "flip" training. With the rapid development of information technology, China is vigorously promoting education informatization construction, especially the construction of "Three - two" platform will completely change the teaching environment and the training environment. Cloud services, cloud and cloud resources will boost reform in primary school classroom teaching mode and teacher training mode; information teaching environment not only for the "primary and secondary classroom flip, but also provides rich teaching resources and a full range of interactive form of" flip "teacher training.

Secondly, teaching of information technology provides a method to "flip" training. The Internet and modern mobile information communication tools increasingly changing people's life, work and learning; remote network and mobile communication, is a new generation of teachers (including teachers training) the common way of life. Teachers and students can not only through the school. 
Internet cafes or personal computer, but also through the mobile phone, iPad and other online learning. Whenever and wherever possible teaching video recording and playback, learning resources upload and download "flip" the basic training conditions are more and more teachers to grasp and use.

According to the characteristics and status quo of mathematics teaching of secondary vocational school students, on the basis of theoretical and practical significance on teaching behavior research of teachers in the classroom and the turnover of effective teaching and effective teaching and research review, research ideas and presupposition. By using literature method, questionnaire survey method and action research method about teachers in flipped classroom teaching to study the behavior of teachers under the flipped classroom teaching strategies and effective teaching strategies of mathematics teaching is discussed under the flipped classroom, the establishment of "evaluation system" flipped classroom teaching process -- Reflection after class teacher -- Optimization of flipped classroom model.

\section{Summary}

School education is transformed into "Internet education." "Internet." Policy and task-driven in the background may promote the education administration to pay more attention to the Internet educational resources and the information-based means to infiltrate into the classroom education. "Transformation" is not equal to "substitution". School and network are very different fields. It is necessary to carefully examine the influence of the two fields on teachers, students and teaching interaction, and choose carefully on the basis of comparison and balance.

The flipped classroom is currently a new mode of education, but also solve the current situation of low efficiency in mathematics teaching in secondary vocational mathematics teaching. Especially, is particularly important, it is decided by the learning environment of students of secondary vocational school students, vocational students are different from the ordinary high school students as learning pressure, time is pressing.

\section{References}

[1] Zhong Xiaoliu and so on. Research on the teaching design based on the concept of overturned class in the information environment. Open education research, 2013 (2):150-162.

[2] Zhang Jinlei , Wang Ying , Zhang Baohui ; inverted classroom teaching mode research ; Journal of Distance Education ; April 2012.

[3] Zhang Jiulu, Chen Zhenguo . An empirical study on the effect of turnover class on teaching quality: taking physics teaching as an example. Shanghai Educational Scientific Research, 2014 (10): $48-50$.

[4] Zhang Jinlei et al.Study on the Mode of flipping classroom Teaching. [J] .Journal of distance Education, 2014, 2(3):38-54.

[5] Ping - wei fang, vocational school mathematics turn - over classroom teaching exploration and practice , J school , Asia - Pacific education , 201518.

[6] Yang Gang, Yang Wenzheng, Chen Li; Ten wonderful cases of "flipping classroom" [J]; IT education in primary and secondary schools; No. 03 of 2012. 